\title{
Detection of shift in binaural images: A rating method approach
}

\author{
LLOYD F. ELFNER ${ }^{2}$ AND WILLIAM R. DELAUNE \\ FLORIDA STATE UNIVERSITY
}

\begin{abstract}
Two practiced listeners were run in a lateralization task in which a rating method was employed. The detection of right and left shifts from the center position was determined. The effect of frequency of the signal was also assessed in the lateralization task. In addition, nine naive listeners were run in a similar situation in order to determine the feasibility of the use of the rating method approach with untrained Ss. First-half, second-half comparisons were determined to check reliability of the technique and also to evaluate the effect of number of trials. The experimental results indicate the procedure is a promising one for the study of directional shifts in binaural stimuli with practiced listeners.
\end{abstract}

Binaural lateralization is the phenomenon associated with the presentation of a signal to each ear of the listener via earphones. If two identical signals with no phase difference are presented simultaneously to each ear, a single auditory image is sensed along the midline of the head. A change in intensity at one ear will cause the sound image to shift in position toward the ear receiving the more intense signal. In this study, the method of increasing the intensity of the signal at one ear and decreasing the intensity of the signal at the other ear was employed (Elfner \& Tomsic, 1968a). This procedure has two advantages over changing the intensity at one ear. First, the overall intensity level remains approximately the same; second, the signal varies in intensity at both ears simultaneously rather than at a single ear. It has been demonstrated (Elfner \& Perrott, 1967) that simply reducing the intensity at one ear leads to larger thresholds of just noticeable shift. And, if one increases the intensity at a single ear, change in intensity is confounded with direction of shift.

The application of the rating method (Egan \& Clarke, 1966) to auditory lateralization would appear to be a natural one. The presence of an interaural imbalance (shift) can be considered analagous to the $\mathrm{SN}$ condition, and the absence of an interaural imbalance can be considered analagous to the $\mathrm{N}$ condition in the typical signal-detection task. The response of the $S$ is conditional upon the stimulus condition (an interaural imbalance was present or was not present) and a measure of sensitivity $\left(d_{s}\right)$ can be determined. The advantages of the rating technique over the classical methods are that the measure of sensitivity $d_{s}$ is determined relatively independently of criterion and a measure can be obtained that may at least partially indicate changes in criterion (slope of the best fit line).

Several past studies (Elfner \& Tomsic, $1968 \mathrm{a}, \mathrm{b})$ have shown that threshold of shift is independent of the frequency of the signal. In the above studies, the signals were presented in phase at the two ears, and interaural intensity imbalances were employed. In the natural situation, one would expect both a phase shift and an interaural intensity shift as the signal moves in the lateral plane. Hence, in the lateralization situation above, there is contradictory phase information for low-frequency signals. It is possible that the listener employs a different criterion for lateralizing low and high frequencies. The rating method should provide information as to whether or not sensitivity of the auditory system is different for low and high frequencies in a lateralization task and possibly whether or not criterion changes are present.

\section{PROCEDURE}

In the initial portion of the study, two experienced listeners were employed. The listeners were given extended practice in detection of shift from center of a binaurally produced image at various frequencies. Nine naive undergraduate students enrolled in introductory psychology courses at Florida State University were used in the second portion of the study. The naive listeners were given extended practice in the lateralization task and tested at a single frequency.

A block diagram of the apparatus employed is shown in Fig. 1. The tone, produced by an audio-oscillator (Hewlett-Packard, Model 204B) was split. One portion of the signal was passed through Electronic Switch and Timer No. 1 (Grason-Stadler, Models 829D and 471, respectively). At this point, the signal was further split and each signal was led separately to a decade attenuator (Hewlett-Packard, Model 350D). The signals were then led to an earphone (TDH-49) on opposite sides of a headset located in a soundproof room (IAC, Model 1200) where S listened. (This was the standard signal.) The remaining signal from the original splitting transformer was led to Electronic Switch and Timer No. 2. These signals were then further split. Each of the signals was led separately through precision attenuators (Altec-Lansing, Model DA-8736) that were adjustable in 0.1-dB steps. These signals were led separately through the decade attenuators to transformers and earphones. This was the test signal. A 10-msec rise-decay time was programmed for all signals. A signal-plus-noise trial consisted of a standard signal presented for $1 \mathrm{sec}$ centered in S's head followed by a 1-sec test signal having a 2-dB interaural intensity imbalance. A noise trial consisted of standard signal presented for a period of 1 sec centered in the S's head followed by a test signal presented for a period of $1 \mathrm{sec}$ centered in S's head. An interval timer, activated by an external switch, was used to present a 1-sec-duration light stimulus (a ready signal) to the listener and then to activate the system described above.

Interaural imbalances were presented with right or left direction of shift an equal number of times. A random order of direction of shift was employed except that direction was consistent within a block of trials. A block of trials consisted of 40 presentations equally divided between signal and signal-plus-noise trials (randomly ordered). An intertrial interval of $1.5 \mathrm{sec}$ was employed. Each session consisted of four blocks of trials. Six rehearsal trials were run (three noise, three signal plus noise) preceding each block of trials. One practiced $S$ (LE) was exposed to 720 trials under each condition (all combinations of the three frequencies 500 , 1,000 , and $2,000 \mathrm{~Hz}$, and right and left

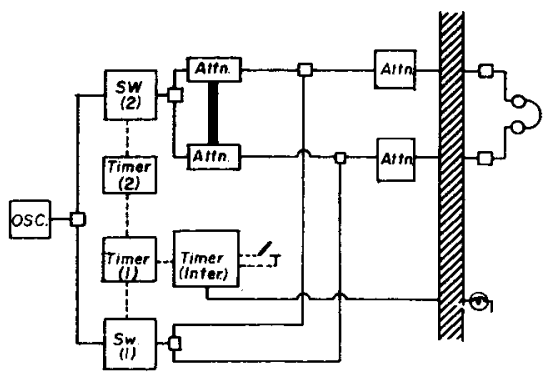

Fig. 1. A block diagram of the apparatus used in the study. 
Table 1

Sensitivity to Detection of Shift in a Binaural Image Demonstrated by Naive Listeners Employing the Rating Method

\begin{tabular}{|c|c|c|c|c|}
\hline Frequency & $\begin{array}{c}\text { S } \\
\text { (Naive) }\end{array}$ & Slope & ds & $\begin{array}{c}\text { SPL Imbalance } \\
\text { (Centered Image) }\end{array}$ \\
\hline $\begin{array}{r}2,000 \\
2,000 \\
2,000 \\
1,000 \\
1,000 \\
1,000 \\
500 \\
500 \\
500\end{array}$ & $\begin{array}{l}1 \\
2 \\
3 \\
4 \\
5 \\
6 \\
7 \\
8 \\
9\end{array}$ & $\begin{array}{l}0.60 \\
1.00 \\
0.61 \\
1.19 \\
1.27 \\
0.60 \\
0.28 \\
1.74 \\
\text { No plot }\end{array}$ & $\begin{array}{l}0.96 \\
0.00 \\
1.38 \\
0.69 \\
0.15 \\
1.35 \\
3.32 \\
1.75\end{array}$ & $\begin{array}{l}+3 \mathrm{~dB} \text { Right } \\
+1 \mathrm{~dB} \text { Left } \\
+ \text { 8dB Right } \\
+7 \mathrm{~dB} \text { Right } \\
+4 \mathrm{~dB} \text { Right } \\
+16 \mathrm{~dB} \text { Left } \\
+2 \mathrm{~dB} \text { Right } \\
+6 \mathrm{~dB} \text { Right }\end{array}$ \\
\hline
\end{tabular}

Table 2

Sensitivity to Detection of Shift in a Binaural Image Demonstrated by Practiced Listeners Employing the Rating Method

\begin{tabular}{|c|c|c|c|c|}
\hline Frequency & $\begin{array}{c}\text { S } \\
\text { (Practiced) }\end{array}$ & Slope & ds & $\begin{array}{l}\text { SPL Imbalance } \\
\text { (Centered Image) }\end{array}$ \\
\hline $\begin{array}{r}2,000 \\
2,000 \\
1,000 \\
1,000 \\
500 \\
500\end{array}$ & $\begin{array}{l}\text { FD } \\
\text { LE } \\
\text { FD } \\
\text { LE } \\
\text { FD } \\
\text { LE }\end{array}$ & $\begin{array}{l}1.07 \\
0.60 \\
1.10 \\
0.66 \\
1.18 \\
0.72\end{array}$ & $\begin{array}{l}0.39 \\
1.34 \\
2.16 \\
1.98 \\
2.50 \\
1.62\end{array}$ & $\begin{array}{l}+11 \mathrm{~dB} \text { Left } \\
+5 \mathrm{~dB} \text { Right } \\
+1 \mathrm{~dB} \text { Right } \\
+11 \mathrm{~dB} \text { Right } \\
+7 \mathrm{~dB} \text { Left } \\
+0 \mathrm{~dB}\end{array}$ \\
\hline $\begin{array}{r}2,000 \\
2,000 \\
1,000 \\
1,000 \\
500 \\
500 \\
1,000 \\
2,000\end{array}$ & $\begin{array}{l}\text { R Shift LE } \\
\text { L Shift LE } \\
\text { R Shift LE } \\
\text { L Shift LE } \\
\text { R Shift LE } \\
\text { L Shift LE } \\
\text { 1 st Half LE } \\
\text { 2nd Half LE }\end{array}$ & $\begin{array}{l}0.58 \\
0.04 \\
0.77 \\
0.57 \\
0.57 \\
0.85 \\
0.30 \\
0.57\end{array}$ & $\begin{array}{l}1.48 \\
0.59 \\
1.48 \\
2.53 \\
1.82 \\
1.42 \\
0.98 \\
1.48\end{array}$ & \\
\hline
\end{tabular}

shifts). The second practiced $S$ was given 320 trials under each experimental condition. The naive $\mathrm{Ss}$ were exposed to 80 trials under each direction of shift at a single frequency to become acquainted with the experimental task. Three naive $S$ s were then run in each frequency condition for a series of 320 trials during testing.

In all cases, $S$ responded by using a rating method in which a number was selected from a 4-point scale. A one response indicated certainty of shift, a two response indicated uncertainty of shift, a three response indicated uncertainty of no-shift, and a four response indicated certainty of no-shift. Accumulated category boundaries were employed to generate a response operating curve for each individual in the naive group and for each condition for the two practiced listeners. The accumulated category boundaries were determined in the following manner: The first abscissa value is the probability of a one response on a noise trial. The second abscissa value is the probability of a two response on a noise trial added to the previous probability. The third abscissa value is the probability of a three response on a noise trial added to the previous accumulated probability. The first ordinate value is the probability of a one response of a signal-plus-noise trial, the second ordinate value is the probability of a two response on a signal-plus-noise trial added to the previous probability, the third ordinate value is the probability of a three response on a signal-plus-noise trial added to the previous accumulated probability. A plot of the obtained points produces a normal ROC function. A $\mathrm{z}$ transformation of the points transforms the plot into a linear arrangement. The best fitting straight line was obtained by the method of least squares. A computer program was employed to determine the slope, the $y$ intercept, and the intercept of the negative diagonal $\left(d_{s}\right)$.

The experimental results are shown in Tables 1 and 2. No plot was available for S 9 as the responses of this listener were all either one or four yielding only one point. However, this listener exhibited a hit rate of $96 \%$ and a false alarm rate of $16 \%$. The most notable result is the high discriminability shown for the $500-\mathrm{Hz}$ signal. Two listeners showed random responses to the $2,000-\mathrm{Hz}$ signal and one listener showed random responses to the $1,000-\mathrm{Hz}$ signal. One practiced listener (LE) was inadvertently run with a 1- and $11 / 2-\mathrm{dB}$ interaural intensity imbalance for the $2,000-\mathrm{Hz}$ condition. The obtained $d_{s}$ was approximately zero, with a slope of one. When the interaural imbalance was

\section{RESULTS}

increased to $2 \mathrm{~dB}$, the $\mathrm{d}_{\mathrm{s}}$ increased to 1.34 . An inspection of the values of the obtained slopes shows an interesting dichotomy. Approximately half of the slopes have values in the neighborhood of 0.6-0.8 and the other half have values in the neighborhood of 1.0-1.2.

In terms of left vs right shift, no clear indication of change in discriminability is apparent. The results of the first-half vs second-half breakdown show a slight increase in sensitivity to shift over the last half of the trials.

Figure 2 is a plot of the ROC function for frequencies of $500,1,000$, and $2,000 \mathrm{~Hz}$, showing sensitivity to shift exhibited by individual naive listeners.

Figure 3 is a plot of the ROC function for the three frequencies, showing discriminability of shift exhibited by Practiced Listener FD. The responses of FD for the 2,000-Hz signal, although only slightly better than random, form a linear pattern that is approximately parallel to the positive diagonal.

Figure 4 is a plot of the ROC functions for discrimination of left vs right shift for Practiced Listener FD for a $1,000-\mathrm{Hz}$ signal. Although the slope constants show a large difference between left and right judgments, the negative diagonal intercept shows only a small difference.

Figure 5 is a plot of the ROC functions for discrimination of shift for Practiced Listener LE. The first-half vs second-half plot of responses to shift are shown for a $2,000-\mathrm{Hz}$ signal. The intercept of the ROC function and the negative diagonal is identical for the second half and the first half of the trial session.

\section{DISCUSSION}

The experimental results demonstrate that the rating method may be usefully applied to the study of auditory lateralization. A plot of the z-transformed values of the accumulated category boundary percentages demonstrates a good linear function. Even in cases where the discrimination was low, the data points demonstrated linearity. If one accepts the slope of the best-fit line as an indicator of listener criterion, it can be seen that the two practiced listeners maintained a fairly stable criterion across frequencies. The results of the split-half test on the 720 trials indicate that there is no improvement in discrimination following the first 360 trials. This finding indicates that with practiced listeners it is possible to obtain reliable performance on the task with relatively few trials. The variable results demonstrated by the naive listeners indicate that extended use of the rating technique is probably necessary to obtain reliable data with this procedure if other than practiced Ss are used. 


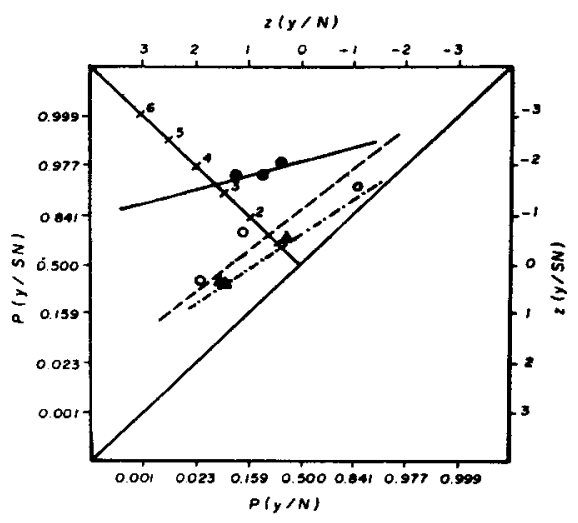

Fig. 2. ROC functions for detection of shift for naive listeners, for frequencies of $500 \mathrm{~Hz}$ (filled circles), $1,000 \mathrm{~Hz}$ (open circles), and $2,000 \mathrm{~Hz}$ (triangles).

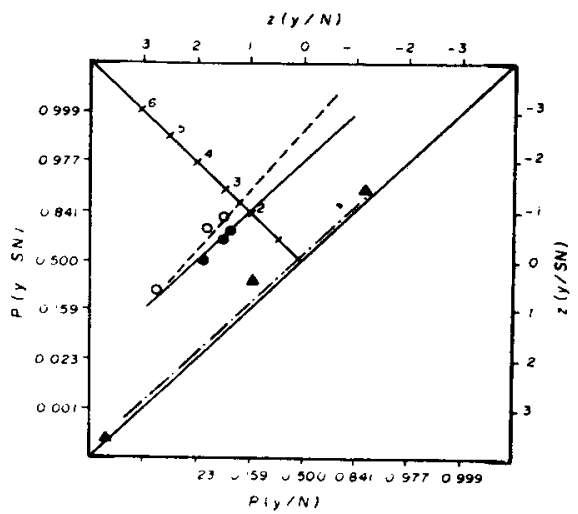

Fig. 3. ROC functions for detection of shift for Practiced Listener FD for frequencies of $500 \mathrm{~Hz}$ (filled circles), $1,000 \mathrm{~Hz}$ (open circles), and $2,000 \mathrm{~Hz}$ (triangles).

The data obtained as a function of direction of shift indicates definite differences in sensitivity. The sensitivity to shift does not seem to be associated with SPL imbalance. Although Listener LE detected right shift for the $2,000-\mathrm{Hz}$ signal, his detection of left shift at this frequency was only slightly better than chance. This listener's sensitivity to a $1,000-\mathrm{Hz}$ signal was much greater at the right than at the left ear, yet the sensitivity to shift was

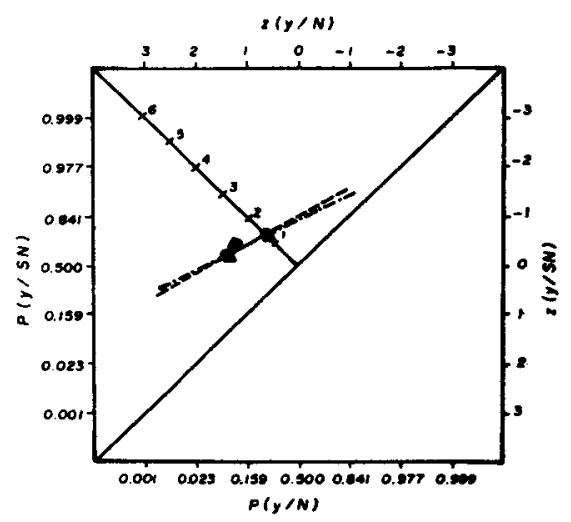

Fig. 4. ROC functions for detection of right (circles) vs left (triangles) shift of 1,000-Hz signal for Practiced Listener FD.

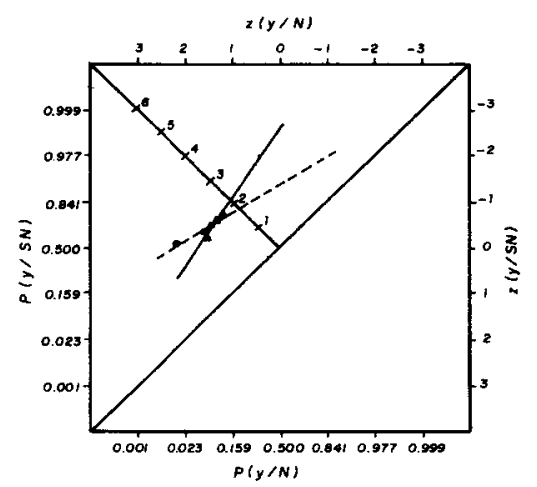

Fig. 5. ROC functions for detection of shift for first half (dot-dash line) vs second half (dash line) of the trials for a $2,000-\mathrm{Hz}$ signal for Practiced Listener LE.

better when shifts were toward the less sensitive ear. Sensitivity to shift does not appear to be related to absolute sensitivity of the ear. However, there is some evidence that when the ears are approximately equal in sensitivity, little difference is noted in $d_{s}$ bewteen right- and left-shift discrimination.

All listeners were able to discriminate shifts in the $500-\mathrm{Hz}$ signal to a $2 \cdot \mathrm{dB}$ interaural intensity imbalance. If one assumes $d_{s}$ is an indicator of sensitivity, then it is apparent that shifts in the low-frequency signal are more easily discriminated than shifts in the higher-frequency signals. The detection of shifts in the $2,000-\mathrm{Hz}$ signal is a difficult task at the interaural intensity imbalance employed. Two listeners were unable to perform at better-than-chance level and one listener could detect shifts in only one direction under this condition. The signals were calibrated to insure that no significant phase differences were produced by the apparatus. Hence, phase information for the low frequencies was not available to the listener. Thus, even in the presence of contradictory phase information (that is, intensity increase without phase shift), the listeners were able to discriminate shifts in the low frequencies at a high level of performance. The apparent difficulty in detection of shift in the $2,000-\mathrm{Hz}$ signal is difficult to explain. In a localization setting, one would expect deterioration of performance at this frequency since head shadow would produce minimal intensity cue and phase cue would be minimal. However, in the lateralization task, the interaural intensity cue is provided to the listener.

\section{REFERENCES}

EGAN, J. P., \& CLARKE, F. R. Psychophysics and signal detection. In J. B. Sidowski (Ed.), Experimental methods and instrumentation in psychology. New York: McGraw-Hill, 1966. Pp. 211-246.

ELFNER, L. F., \& PERROTT, D. R Lateralization and intensity discrimination. Journal of the Acoustical Society of America $1967,42,441-445$.

ELFNER, L. F., \& TOMSIC, R. T. A methodological study of auditory lateralization. Behavior Research Methods \& Instrumentation, 1968a, 1, 7-10.

ELFNER, L. F., \& TOMSIC, R. T. Temporal and intensive factors in binaural lateralization of auditory transients. Journal of the Acoustical Society of America, 1968b, 43, 496-500.

\section{NOTES}

1. This study was supported by Research Grant GB-6815 from the National Science Foundation.

2. Address: Department of Psychology, Florida State University, Tallahassee, Florida 32306.

(Accepted for publication November 17, 1969.) 